\title{
Community College Students' Self-Efficacy and Conceptual Knowledge of Circuit Analysis
}

\section{Dr. Carl Whitesel, Mesa Community College}

Carl Whitesel has spent his career teaching Engineering Technology, and has taught in the community college setting since 2007. He is currently teaching Robotics and Automated Systems within the Arizona Advanced Manufacturing Institute (AzAMI) at Mesa Community College. His teaching focus is primarily on circuit analysis, electronics, motors and sensors. He earned his Ph.D. in Engineering Education Curriculum and Instruction, from Arizona State University in 2014. His primary research interests are conceptual knowledge, concept inventories and self-efficacy.

\section{Dr. Adam R Carberry, Arizona State University}

Dr. Adam Carberry is an assistant professor at Arizona State University in the Fulton Schools of Engineering Polytechnic School. He earned a B.S. in Materials Science Engineering from Alfred University, and received his M.S. and Ph.D., both from Tufts University, in Chemistry and Engineering Education respectively. Dr. Carberry was previously an employee of the Tufts' Center for Engineering Education \& Outreach and manager of the Student Teacher Outreach Mentorship Program (STOMP). 


\section{Community College Students' Self-Efficacy and Conceptual Knowledge of Circuit Analysis}

\section{Introduction}

DC circuit analysis is considered to be a difficult course for many engineering students to understand $^{1}$. Correct conceptual knowledge of this topic is important because it may help students gain expertise in their performance. To date there have been no studies of this topic involving the community college student population. The few studies that have examined community college engineering students have shown self-efficacy to be the one common link with research on the university population ${ }^{2}$. This is rooted in the fact that many of the strategies intended to increase student interest, achievement and persistence in engineering are based on increasing self-efficacy, which is a better predictor of those outcomes ${ }^{2,3}$.

A logical starting point for examining this topic as it relates to community college students is to examine the relationships between conceptual knowledge of DC circuit analysis with selfefficacy for circuit analysis. An instrument was created to measure the relationship between self-efficacy for and conceptual knowledge of DC circuit analysis. The instrument was a threetiered concept-inventory that included:

Tier 1: Multiple choice assessment of understanding related to a DC analysis concepts.

Tier 2: Multiple choice question regarding subjects' reasoning for their response in the first tier, with an option for them to write a response in their own words. Tier 3: Questions related to subjects' confidence in their answers to the first two tiers. Responses were via a 100-point range on a Likert scale with 10-unit increments.

This multi-tiered approach was consistent with prior approaches in the literature ${ }^{4,5}$.

This paper extends the work of others by applying prior research on self-efficacy and conceptual knowledge of circuit analysis to a community college engineering student population.

\section{Literature Review}

\section{Self-Efficacy}

Many research studies in engineering education use self-efficacy theory to frame student motivation. Self-efficacy is a context-specific predictor of performance ${ }^{6}$ that is based on confidence about one's capabilities to organize and implement actions necessary to attain desired performance $^{7}$. A key component of self-efficacy is its context and domain specificity ${ }^{8}$; the more specific a domain is, the more specific one can determine self-efficacy. 
Self-efficacy is also a significant contributor to performance ${ }^{9}$ having been observed in many domains (e.g., academic achievement ${ }^{10}$ and achievement goals ${ }^{11}$ ). Self-efficacy has also been shown to be a powerful contributor to academic attainment that is independent of knowledge and skills $^{12}$, however, people must have some prior knowledge of the task they are considering in order to be self-efficacious. Prior knowledge provides familiarity with the task and the actions required to perform that task ${ }^{10}$.

Self-efficacy includes confidence as well as one's perceived capabilities to organize and implement actions necessary to attain desired performance ${ }^{7}$. Thus, self-efficacy is a reflection of one's confidence to succeed at a task in the context of a domain ${ }^{12}$. Confidence can be a measure of self-efficacy, as the more confident one is in a domain, the more certain they are in their responses to questions about that domain ${ }^{5}$.

\section{Conceptual Knowledge}

Conceptual knowledge has been extensively studied, particularly in the field of Physics Education ${ }^{13}$. Concepts are the organizers that sort our prior knowledge so we have an idea of what to expect when we encounter something new ${ }^{14}$. Conceptual knowledge is the understanding or interpretation one may have about concepts. This can then be carried into future situations, providing the holder with an idea of what to expect in that situation ${ }^{15}$. Conceptual knowledge can be related to the "Understanding" level of Bloom's Taxonomy ${ }^{16}$. While this level is not often considered to be difficult for students, it is one of the foundations of higher learning. Higher thought is likely to be clouded if that foundation is weak, unclear, or misunderstood ${ }^{15}$. When concepts are well-understood, students are often able to explain related problems, make inferences from the problem, integrate other ideas, predict outcomes and apply conceptual knowledge to other areas ${ }^{17}$.

The ability to measure conceptions can help engineering educators address misconceptions instead of assuming that concepts are understood, or worse, leaving those misconceptions in place, to possibly influence future learning in a negative way ${ }^{17}$. Misconceptions can make it extremely difficult for students to accept and learn new information, which is why identification of those misconceptions is so important ${ }^{18}$.

One way to measure conceptual knowledge is through the use of concept inventories. Concept inventories are standardized exams designed to identify common misconceptions students may hold about concepts within a specific domain ${ }^{19}$. Concept inventories allow rapid assessment of conceptual knowledge ${ }^{1}$, and allow assessment of conceptual understanding, as opposed to assessing the ability to work a problem correctly ${ }^{20}$. Results from concept inventories are accepted by the Accreditation Board for Engineering and Technology (ABET) as proof of student learning and achievement ${ }^{19}$.

The use of concept inventories is well-established in the literature ${ }^{21}$, and is used in such domains as Statics, Dynamics, Fluid Mechanics, Heat and Energy, Heat Transfer, Thermodynamics, 
Materials, Circuit Analysis, Electricity, Electricity and Magnetism, Statistics ${ }^{22}$. Using concept inventories to assess conceptual knowledge of voltage, current and the physical characteristics of DC circuits is a common approach in engineering education. There are at least thirteen published concept inventories used to measure various concepts within electrical engineering. The particular concepts of voltage, current and the physical characteristics of DC circuit analysis have been identified in the literature as being particularly difficult for students to learn ${ }^{5,23,24}$.

\section{Self-Efficacy and Conceptual Knowledge}

High self-efficacy has been shown to influence high academic achievement, which implies selfefficacy and conceptual knowledge are related. Studies involving conceptual knowledge and self-efficacy are common and well-developed in engineering education research. The majority of this research has been limited to university student populations with a smaller body of work that has focused on the general community college population. No research has been done investigating circuit analysis and self-efficacy on the community college student population.

\section{Methods}

\section{Study Context and Participant Population}

This study was conducted at a large community college in the southwestern United States. Students from three introductory circuit analysis courses in the Electronics program were studied. Participation was voluntary. There was a potential population of 48 students solicited to participate in the pre-test, of which, $44(\mathrm{n}=44)$ subjects participated. Attrition of the course of the semester resulted in a potential population of 41 for the post-test, of which $37(n=37)$ subjects participated. Table 1 summarizes the three groups of participants for both pre and posttests.

Table 1. Section Sample Sizes for Pre- and Post-test

\begin{tabular}{l|l|l}
\hline Section & Pre-test Sample Size & Post-test Sample Size \\
\hline ELE 111 (morning) & 14 & 14 \\
\hline ELE 100 & 12 & 10 \\
\hline ELE 111 (evening) & 18 & 13 \\
\hline Total & $\mathbf{4 4}$ & $\mathbf{3 7}$ \\
\hline
\end{tabular}

Four students, all enrolled in ELE 111, were female. All four female students from the pre-test remained in the study throughout. All participants were classified by the institution as freshmen or sophomores.

\section{Data Collection}

A concept inventory was created to measure the relationships between conceptual knowledge of DC circuit analysis and self-efficacy for DC circuit analysis. The instrument was a combination 
and adaptation of 15 concept inventory questions from prior work found in the literature.

Questions were included by adapting questions related to voltage and the physical characteristics of circuits from the Determining and Interpreting Resistive Electric Circuit Concepts Test 1.0 (DIRECT) ${ }^{23,25}$, and questions pertaining to current from the Simple Electric Circuits Diagnostic Test (SECDT) ${ }^{5}$. Each item consisted of three tiers of questions and response choices. The first tier was a multiple choice question that measured ability to work a problem related to the concept being assessed. The second tier was a multiple choice question that measured the reasoning the subjects used in answering the first tier. The third tier was a newly developed measure of selfefficacy.

The items used in the concept inventory did not change between pre and post-tests. An example of a first-tier question is shown in Figure 1. This was taken from the DIRECT 1.0 and used as item number five on the instrument as a test of conceptual knowledge of voltage ${ }^{23}$.

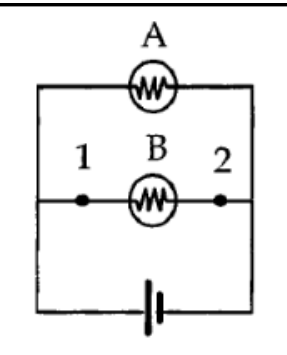

Referring to the figure above, what happens to the potential difference between points 1 and 2 if Bulb $A$ is removed? Circle the letter next to your answer.
a. Increases
b. Decreases
c. Stays the same

\section{Figure 1. Sample First-Tier Item}

The second-tier item that corresponds with the first-tier in Figure 1 is shown in Figure 2. The item is a multiple choice question with one response that matches the correct concept, with the remaining responses matching the misconception distractor items from the first tier. Each second tier item of the concept inventory also included an opportunity for students to explain their reasoning for their response in the first tier. Students were instructed to write their reasoning in the space provided if none of the given response choices matched their reasoning. This item was created to accompany the first-tier because the DIRECT 1.0 did not use this tiered approach. This item was created using the work of Peşman and Eryilmaz ${ }^{4,5}$ as a guide.

The third tier of the concept inventory was a measure of the students' confidence, which was used to gauge self-efficacy for circuit analysis. Responses were reported using a 100-point range on a Likert scale with 10-unit intervals. Prompts were provided at " 0 - Not at all confident", "40 - Maybe-Not Sure", "70 - Pretty Confident", and "100 - Completely Confident". This was consistent with prior approaches in the literature ${ }^{5,12,26}$. An example of a third-tier item is shown 
Which one of the following is the reason for your answer in the first part? Circle the letter next to your answer.

a. The battery provides the same amount of current to each circuit, regardless of the circuit arrangement.

b. Parallel connections have the same voltage.

c. Since the bulbs are equal, removing bulb A leaves twice as much current for bulb B.

d. By removing bulb A, there is more current in the circuit, and thus more voltage for bulb B.

e.

\section{Figure 2. Sample Second-Tier Item}

in Figure 3. Like the previous item examples, it also corresponds with the fifth item on the assessment.

How confident are you about your answers given for parts 1 and 2? Circle the number that best matches how confident you are.

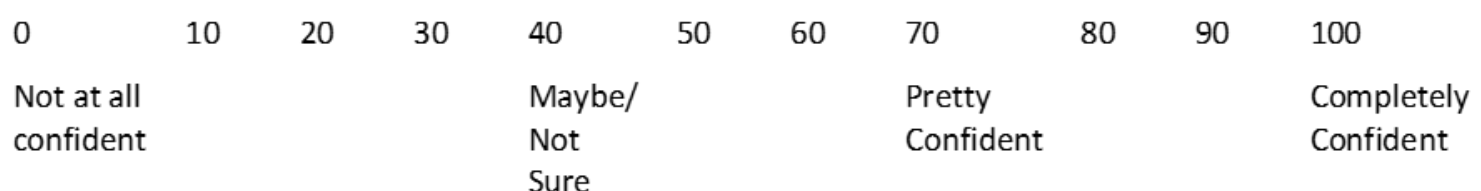

\section{Figure 3. Sample Third-Tier Item}

\section{Scoring}

Scoring for conceptual knowledge was based on combining the scores of the first two tiers. A correct response on both of the first two tiers was scored as a correct answer for the entire question because the subject got the right answer using the correct conceptual knowledge. Any other combination that included a wrong response for either, or both, of the first and second tiers was scored as a wrong answer for the entire question because of incorrect application of the concept, incorrect conceptual knowledge, or both. This scoring method also has the advantage of reducing the chance of a subject getting a correct response by simply guessing, as the probability of correctly guessing two correct responses is less than the probability of guessing one correctly. This scoring approach is consistent with the method used by the authors of the $\mathrm{SECDT}^{4}$.

The third-tier responses were scored by simply recording the raw values from the Likert scale directly into the source file for the data analysis. There were no instances of subjects leaving third-tier responses blank or providing multiple responses. 


\section{Data Analysis}

SAS statistical analysis software was used to analyze the data. Internal reliability of the instrument was checked for both pre and post-tests, and was found to be excellent $(\alpha=0.935)$. Face and content validity for the first two tiers were established via the research performed by the authors of the source concept inventories (DIRECT and SECDT). Face and content validity for the third tier questions were established via research on past studies that used this approach for domains outside of circuit analysis. Construct validity for the instrument was not established due to the low number of subjects and the large number of demographic characteristics measured. To ensure consistency between pre and post-test, only those subjects who participated in both the pre and post-tests were included in the data set. Group effects for the population from the three separate classes were analyzed using Analysis of Variance (ANOVA). No differences were present for the pre-test $[\mathrm{F}(2,36)=0.50, \mathrm{p}=0.612]$ or the post-test $[\mathrm{F}(2,36)=$ $0.20, \mathrm{p}=0.817]$.

\section{Findings}

The data set was analyzed for correlation between self-efficacy for and conceptual knowledge of circuit analysis. Self-efficacy was significantly correlated with conceptual knowledge. This was observed on both the pre-test $(\mathrm{R}=0.42, \mathrm{p}=0.010)$ and post-test $(\mathrm{R}=0.42, \mathrm{p}=0.009)$, as shown in Table 2. In both cases this represents a moderate ${ }^{27}$ and positive correlation, explaining $17.64 \%$ of the variance in pre-test conceptual knowledge scores, and $17.64 \%$ of the variance in post-test conceptual knowledge scores. This finding is consistent with the literature regarding self-efficacy and academic achievement.

Table 2. Pre and Post-Test Concept Inventory and Self-Efficacy Correlations

\begin{tabular}{l|c|c}
\hline \multicolumn{1}{c|}{ Measures } & Correlation & p-value \\
\hline CI and SE scores (Pre) & 0.42 & 0.010 \\
\hline CI and SE scores (Post) & 0.42 & 0.009 \\
\hline
\end{tabular}

\section{Discussion and Conclusions}

The results of this study indicate that conceptual knowledge of circuit analysis and self-efficacy for circuit analysis are directly correlated. One explanation for the correlation observed in this study between conceptual knowledge and self-efficacy may be related to feedback the students received from their instructors. Prior to giving the post-test to each of the classes, the instructors of the ELE 100 and evening ELE 111 classes tested their students on the concepts assessed by the study. Students had not yet received their exam results when the post-test was administered. The morning ELE 111 instructor tested his students on several of the concepts assessed by the study. The students received those results prior to participating in the post-test. Self-efficacy 
may have been impacted if students perceived that feedback as a source of verbal persuasion or evidence of a mastery experience ${ }^{8,28}$, which corresponded with increased conceptual knowledge of circuit analysis.

A limitation of the study was the fact that the statistical methods used in this study rely on normal distribution of data. The existing data set cannot definitively be called "normal" because of the small sample size. The only way to correct this is to conduct a longitudinal study that collects more data over a longer time period.

The relationship between self-efficacy and academic achievement is well known and has been studied for many years ${ }^{11,12,28,29,30,31,32,33}$, however, it has not previously been studied in regard to conceptual knowledge of DC circuit analysis and this unique population of community college students. This is a major gap that has been addressed by the present study, which confirms the same relationship in this population.

\section{Bibliography}

${ }^{1}$ Streveler, R., Litzinger, T. A., Miller, R. L., \& Steif, P. S. (2008). Learning Conceptual Knowledge in the Engineering Sciences: Overview and Future Research Directions. Journal of Engineering Education, 97(3), 279-294.

${ }^{2}$ Jones, B. D., Paretti, M. C., Hein, S. F., \& Knott, T. W. (2010). An Analysis of Motivation Constructs with FirstYear Engineering Students: Relationships Among Expectancies, Values, Achievement, and Career Plans. Journal of Engineering Education, 99(4), 319-336.

${ }^{3}$ Schull, P. J., \& Weiner, M. (2002). Thinking Inside the Box: Self-Efficacy of Women in Engineering. International Journal of Engineering Education, 18(4), 438-446.

${ }^{4}$ Peşman, H. (2005). Development of a Three-Tiered Test to Assess Ninth Grade Students' Misconceptions About Simple Electric Circuits. Master's Thesis, Middle East Technical University, Graduate School of Natural and Applied Sciences, Ankara.

${ }^{5}$ Peşman, H., \& Eryilmaz, A. (2010). Development of a Three-Tier Test to Assess Misconceptions About Simple Electric Circuits. The Journal of Educational Research, 103, 208-222.

${ }^{6}$ Bong, M. (2001). Role of Self-Efficacy and Task-Value in Predicting College Students' Course Performance and Future Enrollment Intentions. Contemporary Educational Psychology, 26, 553-570.

${ }^{7}$ Bandura, A. (1997). Self-Efficacy: The Exercise of Control. New York, NY, USA: Freeman.

${ }^{8}$ Vogt, C. M., Hocevar, D., \& Hagedorn, L. S. (2007). A Social Cognitive Construct Validation: Determining Women's and Men's Success in Engineering Programs. The Journal of Higher Education, 78(3), 337-364. 
${ }^{9}$ Bandura, A., \& Locke, E. A. (2003). Negative Self-Efficacy and Goal Effects Revisited. Journal of Applied Psychology, 88(1), 87-99.

${ }^{10}$ Pajares, F. (1996). Self-Efficacy Beliefs in Academic Settings. Review of Educational Research, 66(4), 543-578.

${ }^{11}$ Liem, A. D., Lau, S., \& Nie, Y. (2008). The Role of Self-Efficacy, Task Value, and Achievement Goals in Predicting Learning Strategies, Task Disengagement, Peer Relationship, and Achievement Outcome. Contemporary Educational Psychology, 33, 486-512.

${ }^{12}$ Pajares, F. (2009). Motivational Role of Self-Efficacy Beliefs in Self-Regulated Learning. In D. H. Schunk, \& B. J. Zimmerman (Eds.), Motivation and Self-Regulated Learning: Theory, Research and Applications (pp. 111-139). New York, NY, USA: Taylor \& Francis.

${ }^{13}$ Wieman, C. (2006). Science Education for the 21st Centry; A Scientific Approach to Science Education. In C. Roos, H. Haffner, \& R. Blatt (Ed.), Atomic Physics 20, XX International Conference on Atomic Physics; ICAP 2006 (pp. 19-26). American Institute of Physics.

${ }^{14}$ Perkins, D. (2006). Constructivism and Troublesome Knowledge. In J. H. Meyer, \& R. Land (Eds.), Overcoming Barriers to Student Understanding: Threshold Concepts and Troublesome Knowledge. New York, NY, USA: Routledge.

${ }^{15}$ Demirci, N. (2010). The Effect of Web-Based Homework on University Students' Physics Achievements. The Turkish Online Journal of Educational Technology, 9(4), 156-161.

${ }^{16}$ Matthews, M. (Ed.). (1998). Constructivism in Science Education: A Philosophical Examination. Dordrecht: Kluwer.

${ }^{17}$ Taraban, R., DeFinis, A., Brown, A. G., Anderson, E. E., \& Sharma, M. P. (2007). A Paradigm for Assessing Conceptual and Procedural Knowledge in Engineering Students. Journal of Engineering Education, 96(4), 335-345.

${ }^{18}$ Martin-Blas, T., Seidel, L., \& Serrano-Fernandez, A. (2010). Enhancing Force Concept Inventory Diagnostics to Identify Dominant Misconceptions in First-Year Engineering Physics. European Journal of Engineering Education, 35(6), 597-606.

${ }^{19}$ Simoni, M. F., Herniter, M. E., \& Ferguson, B. A. (2004). Concepts to Questions: Creating an Electronics Concept Inventory Exam. Proceedings of the 2004 American Society for Engineering Education. Salt Lake City: American Society for Engineering Education.

${ }^{20}$ Hake, R. (2007). Should We Measure Change? Yes! In R. Hake, Evaluation of Teaching and Student Learning in Higher Education. American Evaluation Association.

${ }^{21}$ D'Avanzo, C. (2008). Biology Concept Inventories: Overview, Status, and Next Steps. BioScience, 58(11), pp. 1079-1085. Retrieved from www.biosciencemag.org

${ }^{22}$ Purdue University. (2011). CIHub. Retrieved 11 3, 2012, from CIHub.org: https://cihub.org/

${ }^{23}$ Engelhardt, P. V. (1995). Diagnostic Electric Circuits Test V1.O. North Carolina State University, Department of Physics, Raleigh. 
${ }^{24}$ Streveler, R., Geist, M., Ammerman, R., Sulzbach, C., Miller, R., Olds, B., \& Nelson, M. (2006). Identifying and Investigating Difficult Concepts in Engineering Mechanics and Electric Circuits. Proceedings of the 2006 ASEE Annual Conference. Chicago: American Society for Engineering Education.

${ }^{25}$ Engelhardt, P. V., \& Beichner, R. J. (2004). Students' Understanding of Direct Current Resistive Electrical Circuits. American Journal of Physics, 72(1), 98-115.

${ }^{26}$ Carberry, A. R., Lee, H.-S., \& Ohland, M. W. (2010). Measuring Engineering Design Self-Efficacy. Journal of Engineering Education, 99(1), 71-79.

${ }^{27}$ Taylor, R. (1990). Interpretation of the Correlation Coefficient: A Basic Review. Journal of Diagnostic Medical Sonography, 6(1), 35-39.

${ }^{28}$ Bandura, A. (1977). Self-Efficacy: Toward a Unifying Theory of Behavioral Change. Psychological Review, 84(2), 191-215.

${ }^{29}$ Brown, S. D., Lent, R. W., \& Larkin, K. C. (1989). Self-Efficacy as a Moderator of Scholastic Aptitude Academic Performance Relationships. Journal of Vocational Behavior, 35, 64-75.

${ }^{30}$ Bandura, A. (1993). Perceived Self-Efficacy in Cognitive Development and Functioning. Educational Psychologist, 28(2), 117-148.

${ }^{31}$ Peterson, T. O., \& Arnn, R. B. (2005). Self-Efficacy: The Foundation of Human Performance. Performance Improvement Quarterly, 18(2), 5-18.

${ }^{32}$ Goldstein, M. T., \& Perin, D. (2008). Predicting Performance in a Community College Content-Area Course from Academic Skill Level. Community College Review, 36(2), 89-115.

${ }^{33}$ Bembenutty, H. (2009). Academic Delay of Gratification, Self-Regulation of Learning, Gender Differences, and Expectancy-Value. Personality and Individual Differences, 46, 347-352. 